\title{
Long-term experiences with pluvial flood risk management
}

\author{
Kathrina Fritsch ${ }^{1, a}$, André Assmann ${ }^{1}$ and Bernd Tyrna ${ }^{1}$ \\ ${ }^{1}$ geomer GmbH, Im Breitspiel 11B, 69126 Heidelberg, Germany
}

\begin{abstract}
The awareness of pluvial (rain-related) flood risk has grown significantly in the past few years but pluvial flooding is not handled with the same intensity throughout Europe. A variety of methods and modelling technologies are used to assess pluvial flood hazard and risk and to develop suggestions for flood mitigation measures. A brief overview of current model approaches is followed by the description of a modelling methodology that has been developed throughout the last 15 years with the focus on processing large scale areas. Experiences from several projects show that only high quality models of whole catchment areas yield results with enough accuracy to gain credibility among stakeholders, planners and the public. As a best practice example shows, the model approach also helps to plan effective decentral flood protection measures. To ensure successful flood risk management, a long-term preservation of flood risk awareness among local authorities and the public is necessary.
\end{abstract}

\section{Introduction}

The growing interest in pluvial flooding over the last 10 years has resulted in a number of pilot studies and research projects to assess pluvial flood hazard and risk in a number of European countries (e.g. URBAS 2008 [1]). The works range from small scale research studies using complex models and high resolution data [2] to large scale hazard and risk mapping [3]. Besides the fact that there is no common standard concerning the content and underlying methodology of pluvial flood hazard and risk maps, there are also considerable differences regarding the efforts in European countries to deal with pluvial flooding. Starting with a brief discussion of the societal and political context, the main focus of this paper is to provide an insight into experiences with pluvial flood risk management in Germany, highlighting the following aspects:

- an evaluation of different modelling approaches to support hazard and risk mapping as well as planning of flood mitigation

- prospects and challenges in the planning and implementation of flood mitigation measures

- conclusions drawn from various pluvial flood risk management processes

\section{Situation and perspectives}

\subsection{European context}

As considered in the Framework of the EU flood directive (paragraph 10, [4]) the management of different flood risks should be determined by the member states themselves and should be based on local and regional circumstances. Within this context pluvial flood risk is not handled with the same intensity throughout Europe. Whereas in some countries, e.g. the UK there are efforts to map pluvial flood hazard and risk on larger scales up to the national level [5], authorities in other countries acknowledge the problem, but seem to be apprehensive to tackle it on a large scale.

One reason that governmental agencies refrain from setting up programs to assess pluvial flood hazard and risk may be that even though there exist a variety of methods [5-12], there is no established standard approach within the European Community. Furthermore, in the last years governmental agencies were busy to prepare flood risk management plans for fluvial flooding and thus were not willing or able to invest resources in pluvial flood risk management.

\subsection{National Level}

Although there is not yet a nation-wide assessment of pluvial flood risk management, the German Water Association (DWA) set up different working groups with the aim to establish technical standards and provide affected interest groups with guidelines and practical advice.

With the focus on heavy rainfall events and the common task for flood prevention in communities at a regional level, a guideline was published in cooperation between the German Water Association and the Association of Engineers for Water Management, Waste Management and Land Improvement (BWK) [13]. This guideline summarizes the challenges and possibilities for effective flood prevention and describes practically

\footnotetext{
${ }^{\mathrm{a}}$ Corresponding author: kfritsch@geomer.de
} 
oriented examples to support local planners and decision makers.

Decentral flood mitigation measures in a catchment play a key role in integrated planning. Besides flood mitigation and runoff reduction the measures have a positive effect on groundwater recharge and erosion control [14].

Results of the decentral flood mitigation working group also influenced the DWA working group on flood risk management, which focusses on methodological approaches for systematical hazard and risk analysis [15].

Referring to these nationally developed and available technical standards, in section 4 some best practice examples are presented with the aim to give an impression of pluvial flood risk management processes over the last years.

\section{Technologies}

\subsection{Modelling approaches for different scales and objectives}

The hazard from pluvial flooding has to be considered systematically to get a reliable overview of the very specific and varying local situations [13]. This is done by using one or a combination of different model approaches. Table 1 provides an overview of current approaches applied in this context and their characteristics. The appropriate application of a model approach depends on the scale, the modelling aim and the availability of data and resources.

As a high-level screening method, terrain analysis based on digital elevation models enables the identification of main flow paths and local sinks which often represent areas of high flow depths and/or high flow velocities. The method is fast, relatively easy to apply and thus enables flood screening for large areas.
However, it clearly has its limitations as it does not model hydraulic processes, as for instance backwater effects, and does not provide any information on flow depths or velocities, which are essential for a thorough hazard and risk analysis.

Other model approaches such as 1D or 2D hydraulic models provide more complex representations of overland flow processes or sewer systems. They differ mainly in their computational effort and application scale. Hydraulic models with High Performance Computing (HPC) technology use multicore processing to reduce computational time and thus are able to process large areas at a high spatial resolution.

\subsection{Applied methodology}

The presented method to identify hazardous areas affected by pluvial flooding is based on a combination of a hydrological and a 2D hydraulic modelling system.

Over the years of improving the calculation of timedependent runoff in a combined raster based modelling approach, a proceeding with three main modules was developed. These three modules are used to simulate surface runoff dynamically and over large areas with different characteristics.

At first, precipitation input has to be defined, as the amount and temporal distribution of rainfall are crucial parameters for the dynamically varying surface runoff. Second, depending on the amount of precipitation the hydrological module calculates runoff coefficents using a simplified infiltration approach based on the Green and Ampt principle [16]. As input for this module land use data, high resolution terrain data and soil data is required.

Runoff coefficents, which vary over time, are used to calculate surface runoff. Overland flow is simulated using a hydrodynamic approach in module three. This hydrodynamic part is embedded in the functionalities of the software FloodArea ${ }^{\mathrm{HPC}}$ [17].

\begin{tabular}{|l|l|l|l|l|l|}
\hline \multicolumn{1}{|c|}{ Model approach } & Type of flooding & $\begin{array}{l}\text { Typical } \\
\text { application scale }\end{array}$ & $\begin{array}{l}\text { Preparation } \\
\text { effort }\end{array}$ & $\begin{array}{l}\text { Computational } \\
\text { effort }\end{array}$ & $\begin{array}{l}\text { Overall } \\
\text { complexity }\end{array}$ \\
\hline Terrain analysis & $\begin{array}{l}\text { pluvial flooding } \\
\text { flash flooding }\end{array}$ & large & small & small & low \\
\hline 1D hydraulic models & flash flooding & medium/large & medium/high & medium & high \\
\hline $\begin{array}{l}\text { Full 2D hydraulic } \\
\text { models }\end{array}$ & $\begin{array}{l}\text { pluvial flooding } \\
\text { flash flooding }\end{array}$ & any & medium/high & high & high \\
\hline $\begin{array}{l}\text { Simplified hydraulic } \\
\text { models }\end{array}$ & $\begin{array}{l}\text { pluvial flooding } \\
\text { flash flooding }\end{array}$ & medium/large & medium/high & medium & medium \\
\hline $\begin{array}{l}\text { 1D-2D coupled } \\
\text { hydraulic models }\end{array}$ & flash flooding & any & high & high & high \\
\hline $\begin{array}{l}\text { Drainage models } \\
\text { (sewer models) }\end{array}$ & pluvial flooding & small & high & medium & high \\
\hline $\begin{array}{l}\text { Integrated models } \\
\text { (Combined overland } \\
\text { flow, sewer and } \\
\text { groundwater models) }\end{array}$ & $\begin{array}{l}\text { pluvial flooding } \\
\text { groundwater }\end{array}$ & Small/medium & high & high & very high \\
\hline
\end{tabular}

Table 1. Overview and evaluation of modelling approaches 
As a result of the simulation, surface runoff for variable time steps can be requested including the variation of flow concentration, backwater situations and consideration of small relief structures during time.
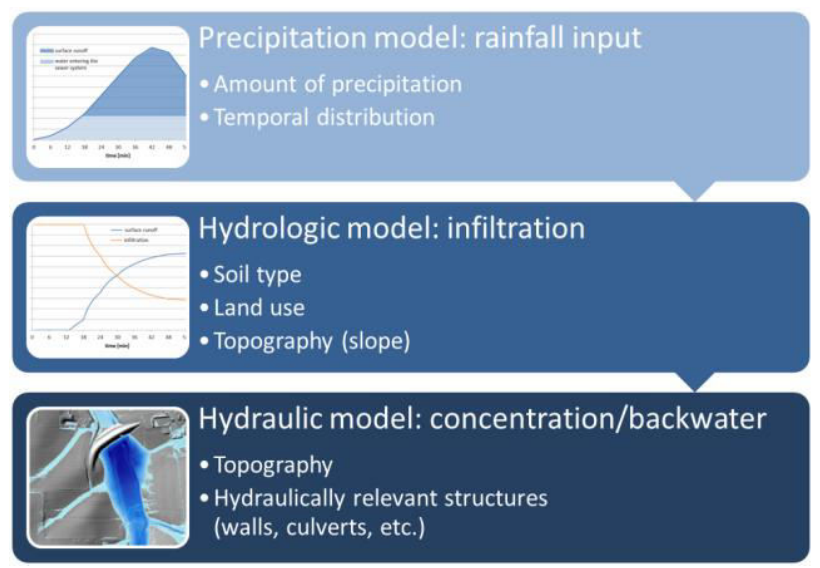

Figure 1. Schematic representation of the 3-step modelling approach.

The described methodology is based on a simplified hydraulic approach with the demand of integrating hydrodynamic calculations, but at the same time handling the simulation of large areas with high resolution data (usually $1 \mathrm{~m}$ ) within an acceptable and realistic time frame.
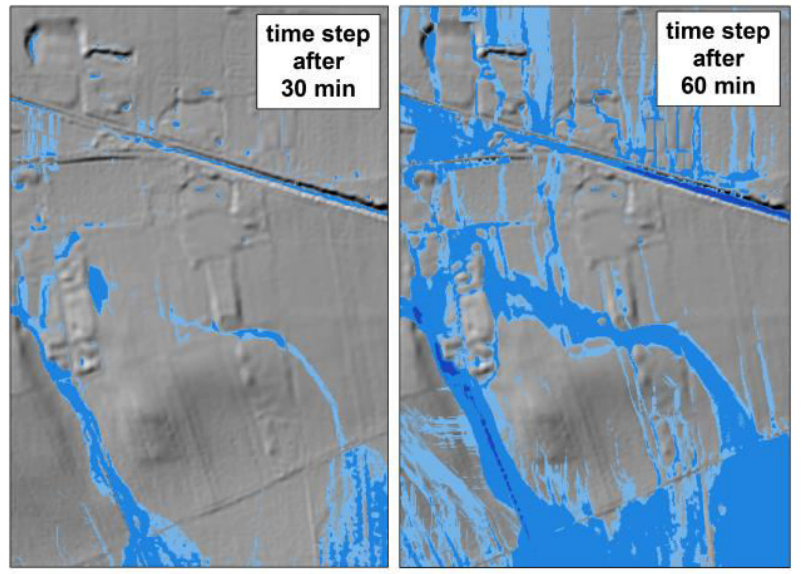

Figure 2. Exemplary flow depth output data for two time steps (30 and 60 minutes) of simulating overland flow with FloodArea ${ }^{\mathrm{HPC}}$.

The high resolution is essential for the accuracy of modelling surface runoff, especially in urban areas. The consideration of small structures like low walls or curbs is crucial to analyse flow paths and assess the influence of flow velocity during the simulation of extreme events. With the applied software it is possible to implement linear structures in different ways. Besides the integration in the terrain model it is also possible to use a different dataset for dam structures like walls or a punctual pumping functionality to implement culverts in ditch systems.

HPC technology enables to simulate overland flow for large catchment areas by splitting the calculation area into tiles which are distributed to the processing cores and processed separately [18]. The model configuration (internal and external parameters e.g. tile size, exchange rate between cells, correction of flow paths) is crucial to optimize the simulation time.

Since 2003 this modelling system has been applied in different project areas throughout Europe (Germany, Austria and Switzerland) and also by the Chinese metrological association (Bejing). Large scale simulations of catchment areas up to $3000 \mathrm{~km}^{2}$ e.g. for the Lippeverband in North Rhine Westphalia, Germany or the catchment area of the river Glems in BadenWuerttemberg $\left(300 \mathrm{~km}^{2}\right)$ [11] have been performed to assess pluvial flood hazard and risk. For the community of Sulzfeld different extreme rainfall scenarios were simulated for the implementation of decentral flood measures. Hazard and risk maps were also produced for the cities of Unna and Hörde to support their climate change adaption strategy within the EU Interreg IVB project "Future Cities" (http://www.futurecities.eu/index.php). The experiences and examples mentioned in the following section are based on these projects.

\subsection{Risk management strategies}

The results from the described proceeding are applied to develop different instruments within the risk management process. First of all, hazard maps which illustrate the flooded areas from surface runoff are an essential tool at the beginning of the management process. To initiate an ongoing awareness for example in communities on a regional level, recurring events for public information, interactive web-tools and trained contact persons are essential instruments to fill the risk management process with life and to ensure its continuity.

\section{Lessons learned from long-term experiences}

In the following section some insights from pluvial flood risk management processes will be described and discussed. The examples comprise the integration of flood modelling results of extreme events into planning processes, post event risk communication as an ongoing process to support general awareness and the need for models using high resolution data for general acceptance in the public.

\subsection{High quality models to gain credibility}

The experience from past projects with partners from different backgrounds points to the fact that especially the quality of modelling results and the consideration of detailed data are very important to gain credibility and public acceptance.

For the integration of surface runoff dynamics into planning processes (at best from the very beginning of the planning), a detailed consideration of observed processes in the model configuration is essential. In this context it is interesting to note that experts from a community that commissioned pluvial flood hazard maps explicitly did not require including a detailed consideration of the sewer 
network, as it will not significantly reduce rainfall runoff in the case of an extreme rainfall event. It was agreed to apply a general abstraction from the input rainfall to account for the amount of water entering the sewer system during an event. What is of great importance, however, is the integration of culverts and ditches in the model to ensure a realistic representation of runoff processes.

The example in Figure 3 shows a very simple flood protection measure of a small wall close to an affected kindergarten building in an examined project area. For this area hazard maps have been generated, which point out the depth and direction of the flow paths for an extreme event scenario with a rainfall of $120 \mathrm{~mm}$ within 1 hour. In this case, the detailed surface runoff information helped to pursue planners during the risk management process to implement this simple measure in the existing structures.

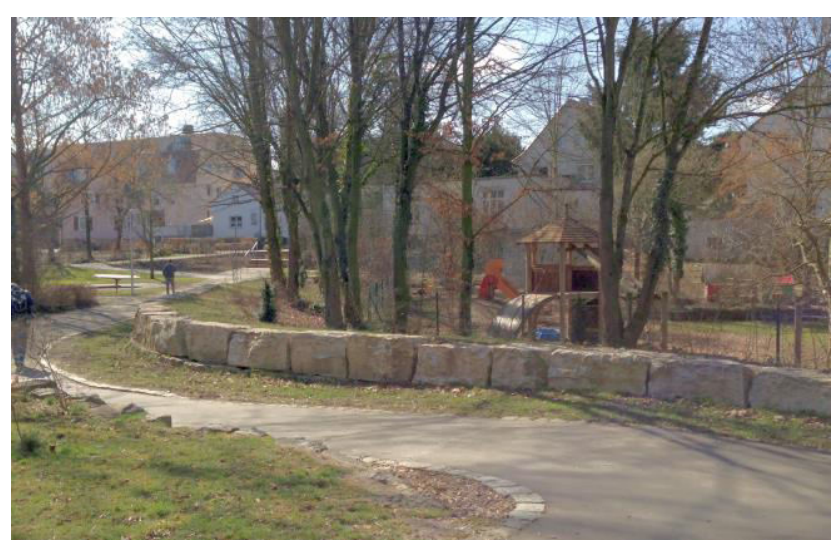

Figure 3. Implementation of flood protection measures (stone wall) into existing structures.

\subsection{Integrated assessment of whole catchment areas}

To get a comprehensive overview of a risk situation, especially in vulnerable urban areas or for a whole community, it is crucial to locate and analyse risk situations from extreme events with all its system components. This is only possible within a modelling concept that includes the whole catchment area to represent flow directions, flow velocities and ponding areas. Analysing smaller parts of affected areas, however, cannot provide reliable information about a complex and dynamic flow situation.

In the following example, the importance of this kind of information is illustrated for the hazard assessment of an object protection measure at a kindergarten [12]. Through the integration of surface runoff information (depth and flow direction) from a pluvial flood risk map into the planning process, the position of the planned measurement (small retention basin) could be optimized and visualised in a map (Figure 4).

In a second example the potential alteration of existing flow paths by a development area were reviewed. During the planning process of a development area the information from a pluvial flood hazard simulation helped to analyse the situation and gave helpful indications for the planners.

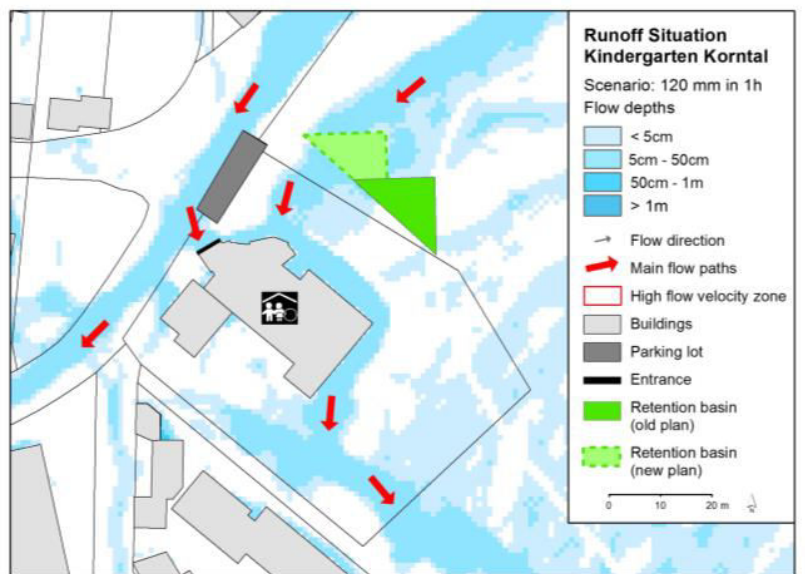

Figure 4. Surface runoff situation at the kindergarten Korntal with planning scenarios for a pluvial flood event of $120 \mathrm{~mm}$ rainfall within $1 \mathrm{~h}$ (adapted from Tyrna, Assmann and Fritsch 2015)

The red arrow in figure 5 shows the flow path from a simulation considering the planned structures. The flow path is leading directly into the planned building of a kindergarten. With the visualisation of this process the planners have the option to find an alternative solution to lead the surface runoff out of the sealed area (e.g. blue arrow) and create a so called emergency runoff pathway.

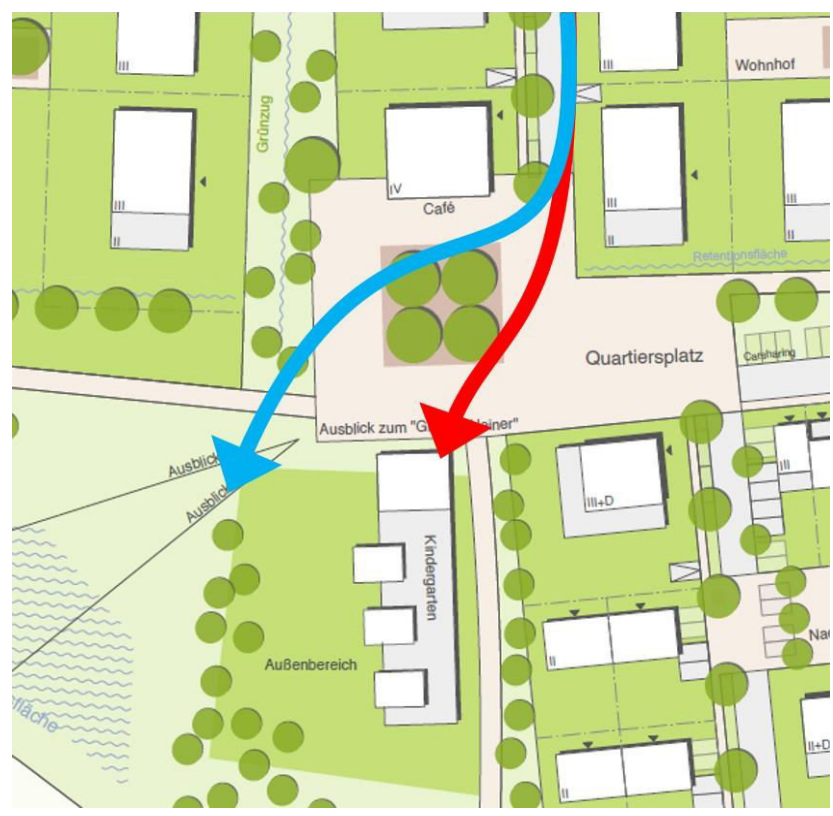

Figure 5. Planning site of a development area with two flowpath options (red and blue arrows).

\subsection{Long-term preservation of risk awareness}

During the supervision of a risk management process for eight communities over several years the experiences show, that the long-term preservation of the risk awareness is strongly dependent on the sensitisation of the person responsible for flooding issues in the community. This is influenced by the personality of the responsible person and his/her level of involvement with the topic of flood risk management in general, as well as on the level of authority this person has within the communal administration. 
The process of flood risk management and referring discussions can only be hold alive through returning events including the public awareness and reminding statements in the relevant working groups.

The live experience of the functioning of an established measure in the community of Sulzfeld has shown that the awareness of the flood risk on the political and also public level is closely linked with the occurrence of an event. After a heavy rainfall event (approx. 20 year return period) had occurred, a concept for decentralised flood protection was developed [19], including a system of retention basins which were built in 2005 . At the end of the construction process and during the dry times the developed concept with small retention basins at different places got critical feedback of the public.

In the year 2013 during a heavy rainfall event with a return period of about 100 years the concept has proven to significantly reduce flood risk (figure 6 and 7) and gained acceptance in public in an impressive way.

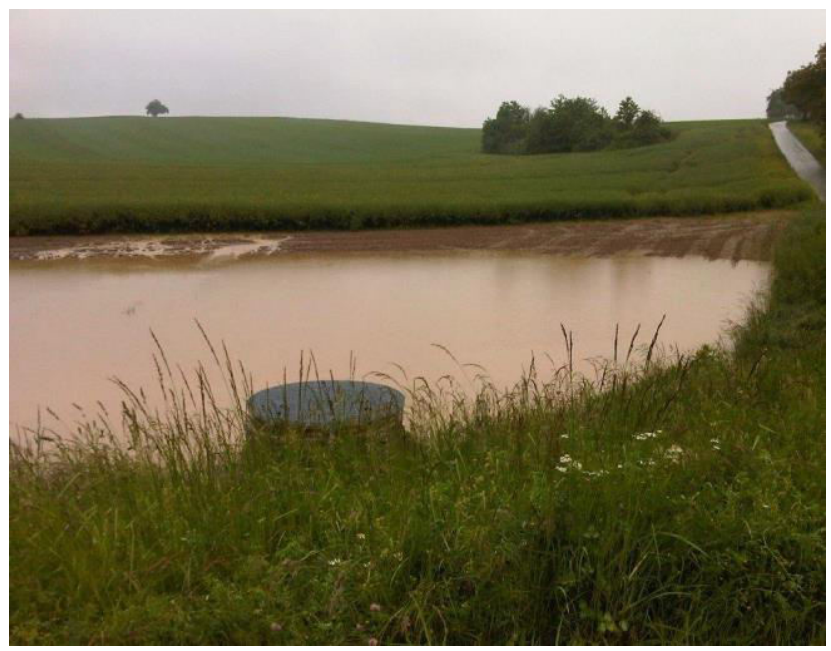

Figure 6. Filled retention basin after a 100 year heavy rainfall event in June 2013 in Sulzfeld (source community of sulzfeld).

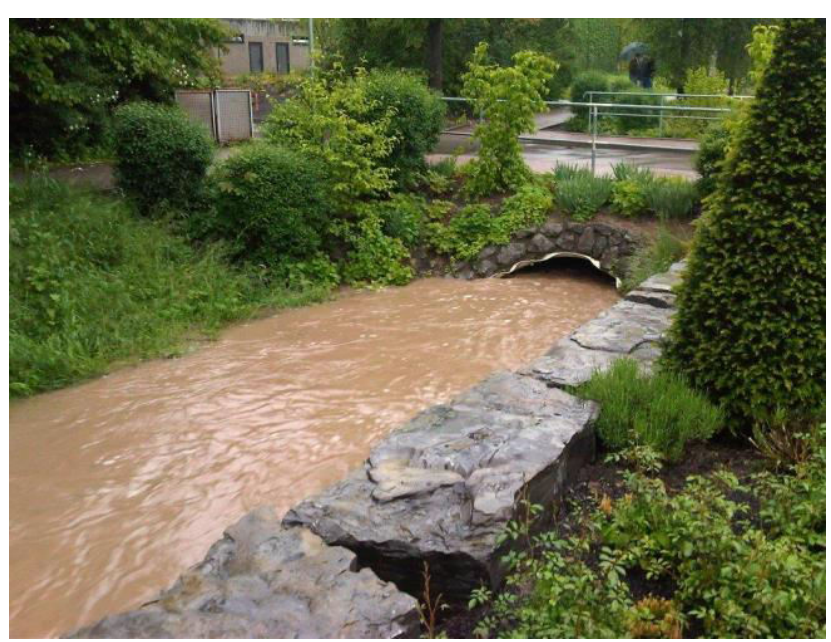

Figure 7. The size of the culvert at the entrance of the village was large enough to safely drain retention basin overflow (right) (source community of sulzfeld).

The implementation of this project was set in the context of the reorganisation of land with the benefit, that all participating actors have been met already at a round table. Therefore extensive coordination processes during the planning and construction phase could be directly discussed with the responsible decision makers.

\subsection{Lessons learned}

Effective Risk management for pluvial flooding has to be treated as a long-term task. The issue of pluvial flooding as an overall risk has to be communicated in a strong and expertise view to persist against other subjects of political and public interest. Therefore the experiences from the past projects have shown that the awareness of the possible hazard is usually present for a short time period after the occurred event. Continued awareness can be improved by returning actions in appropriate administrative levels and depends strongly on the engagement of the representative person. This challenge can be supplied for example by the implementation into standardized processes on an administrative level (e.g. integration of pluvial flooding information in construction permits).

\section{References}

1. URBAS (2008). Prediction and management of urban flash floods.

http://www.urbanesturzfluten.de (last access: 26 Feb 2016).

2. Schmitt, T.G., Thomas, M. and Ettrich, N. (2005). Assessment of urban flooding by dual drainage simulation model RisUrSim. Water science and technology. 52(5), pp. 257-264.

3. Hankin, B., Waller, S., Astle, G. \& Kellagher, R. (2008). Mapping space for water: screening for urban flash flooding. Journal of Flood Risk Management, 1(1), pp. 13-22.

4. European Parliament and Council (2007). Directive 2007/60/EC on the assessment and management of flood risks. Official Journal of the European Union, L 288, pp. 27-34.

5. Houston, D., Werritty, A., Bassett, D., Geddes, A., Hoolachan, A. and Mcmillan, M. (2011). Pluvial (rain-related) flooding in urban areas: the invisible hazard. Joseph Rowntree Foundation, York.

6. Falconer, R.H. and De Hemptinne, F. (2009). EWA expert meeting on pluvial flooding in Europe - Final report. European Water Association, Hennef.

7. Falconer, R.H. (2010). Surface water management in the UK and synergies with the flood resilien city project. IAHR European Congress, Edinburgh.

8. Jacobs (2009a). Improved Understanding of Pluvial Flood Risk in Scotland - Report to SEPA.

9. Jacobs (2009b). London Borough of Richmond upon Thames and Royal Borough of Kingston upon Thames First Edition Surface Water Management Plan - Final Report.

10. Leitão, J.P., Boonya-aroonnet, S., Maksomović, Ĉ., Allitt, R. \& Prodanović, D. (2007). 
Modelling of flooding and analysis of pluvial flood risk - demo case of UK catchment. In Samuels, P., Huntington, S., Allsop, W. \& Harrop, J. (ed) Flood Risk Management: Research and Practice, 48, pp.19-20.

11. A. Assmann, S. Jäger, K. Fritsch \& C. Brauner (2013). Risk maps for pluvial flooding and initiation of a flood risk management process. In F. Klijn \& Scheckendiek (ed) Comprehensive Flood Risk Management. Research for policy and practice: 189. Proceedings of the 2nd European Conference on Flood Risk Management FLOODrisk 2012, Rotterdam.

12. Tyrna, B., Assmann, A. and Fritsch, K. (2015). Starkregen-Risikomanagement in der Praxis (Pluvial flood risk management in practice). Korrespondenz Wasserwirtschaft, 2/15, pp. 102107.

13. Deutsche Vereinigung für Wasserwirtschaft, Abwasser und Abfall e. V. (2013). Starkregen und urbane Sturzfluten - Praxisleitfaden zur Überflutungsvorsorge. DWA-Themenband, 1/2013, p. 61., Hennef.

14. Deutsche Vereinigung für Wasserwirtschaft, Abwasser und Abfall e. V. (2015). Dezentrale Maßnahmen zur Hochwasserminderung. DWA Regelwerk Merkblatt, M 550, Hennef.

15. Deutsche Vereinigung für Wasserwirtschaft, Abwasser und Abfall e. V. (2015). Risikomanagement in der kommunalen Überflutungsvorsorge - Analyse von Überflutungsgefährdungen und Schadenspotenzialen zur Bewertung von Überflutungsrisiken. DWA Regelwerk Merkblatt, draft, M 119, Hennef.

16. Green W.H. and Ampt G.A. (1911): Studies on soil physics I: The flow of air and water in soils. In Journal of Agricultural Science, 4, pp 1-24.

17. Geomer GmbH and RZB GbR (2015). FloodArea and FloodAreaHPC: ArcGIS extension for calculating flooded areas. geomer $\mathrm{GmbH}$, Heidelberg, pp. 67.

18. Assmann A, Schroeder M, Hristov M (2007). High Performance Computing für die rasterbasierte Modellierung (High Performance Computing for raster based modelling). In Strobl $J$, Blaschke T, Griesebner G (ed) Angewandte Geoinformatik 2007, Beiträge zum 19. AGITSymposium Salzburg, pp 19-24.

19. Hettler B. \& Assmann A. (2005). Flood protection by integrated flood protection measures - planning procedure for the communuty of Sulzfeld. In Krimly, T., Dabbert, S. \& Hauser, J. (ed.) Runoff and Erosion management in agriculture - a step towards sustainable flood protection, pp. 41-53. 